\title{
Refractory Cytopenia of Childhood
}

National Cancer Institute

\section{Source}

National Cancer Institute. Refractory Cytopenia of Childhood. NCI Thesaurus. Code C82596.

The most common subtype of the myelodysplastic syndromes affecting children. It is characterized by persistent cytopenia with less than $5 \%$ blasts in the bone marrow and less than $2 \%$ blasts in the peripheral blood. 